\section{LA AGROBIODIVERSIDAD COMO ELEMENTO DE LA SEGURIDAD ALIMENTARIA Y AMBIENTAL}

\author{
Lucía De la Rosa Fernández \\ Instituto Nacional de Investigación y Tecnología Agraria y \\ Alimentaria (INIA) \\ rosa@inia.es \\ Juan Fajardo Vizcayno \\ Instituto Nacional de Investigación y Tecnología Agraria y \\ Alimentaria (INIA) \\ fajardo.juan@inia.es
}

Cómo citar este artículo/Citation: De la Rosa, L. y Fajardo, J. (2016). La agrobiodiversidad como elemento de la seguridad alimentaria y ambiental. Arbor, 192 (779): a316. doi: http:// dx.doi.org/10.3989/arbor.2016.779n3006

Recibido: 08 marzo 2016. Aceptado: 06 mayo 2016.

RESUMEN: En el artículo se revisa la importancia y la situación de la conservación de recursos fitogenéticos para la alimentación y la agricultura, tanto en los aspectos asociados específicamente a esta actividad como en aquellos otros derivados de su faceta como componente de la biodiversidad y proveedor de servicios ecosistémicos. Se incide en la función de las colecciones ex situ como fuente de materiales tanto para su utilización directa como en programas de mejora genética, ambos elementos imprescindibles para una agricultura resiliente frente al cambio ambiental. De forma específica, se describe el estado de la conservación de germoplasma de las especies de la familia de Fabaceae tanto para utilización en alimentación humana como en alimentación animal, en el ámbito nacional e internacional.

PALABRAS CLAVE: Recursos fitogenéticos; leguminosas-grano; colecciones de germoplasma; conservación.

\section{AGRO-BIODIVERSITY AS AN ELEMENT OF NUTRITIONAL AND ENVIRONMENTAL SECURITY}

Copyright: (C) 2016 CSIC. Este es un artículo de acceso abierto distribuido bajo los términos de la licencia Creative Commons Attribution (CC BY) España 3.0.

ABSTRACT: In this article, the importance and situation of the conservation of plant genetic resources for food and agriculture is reviewed, taking into consideration not only the aspects specifically related to the conservation activity but also their role as components of biodiversity and providers of ecosystem services. Special attention is drawn to ex situ collections as providers of germplasm for direct use and for plant breeding, two elements that make an essential contribution to a greater resilience of agriculture to environmental changes. In particular, the state of conservation at national and global levels of genetic resources of Fabaceae species cultivated for human food and animal feed, is examined.

KEYWORDS: Plant genetic resources; grain legumes; germplasm collections; conservation. 


\section{ORIGEN E IMPORTANCIA DE LA AGROBIODIVERSIDAD}

Es indiscutible que la base de la alimentación es la agricultura, y que así es desde que en el Neolítico el hombre cambió su actividad de cazador recolector por la de agricultor. Este periodo, muy dilatado en el tiempo, se podría considerar la Primera Revolución Verde. Desde ese momento, la acción de los procesos naturales de migración, mutación y selección natural, junto con la acción mediada por el hombre sobre las poblaciones primitivas de plantas, dieron lugar a una gran pluralidad y complejidad de formas cultivadas, tanto de especies como a nivel infraespecífico. Esta diversidad agrícola o agrobiodiversidad existe a nivel de ecosistemas, especies y genes y es el resultado de la interacción del ambiente, los recursos genéticos y los sistemas y prácticas de manejo aplicados por las personas, a lo largo de miles de años (FAO, Cómo alimentar al mundo en 2050). La clasificación más frecuentemente utilizada de estos recursos se debe a Esquinas-Alcázar (1993) que los agrupó en: variedades de especies cultivadas, tanto tradicionales (también denominadas locales, autóctonas o criollas) como mejoradas; especies silvestres emparentadas con las cultivadas que pueden contribuir al acervo genético de sus parientes cultivados, y materiales obtenidos en trabajos de mejora genética (stock genético). El Tratado Internacional de Recursos Fitogenéticos para la Agricultura y la Alimentación (TIRFAA) define los recursos fitogenéticos para la alimentación y la agricultura (RFGAA) como "cualquier material genético de origen vegetal de valor real o potencial para la alimentación y la agricultura" (FAO, Tratado Internacional sobre los Recursos Fitogenéticos).

A lo largo del siglo XX una serie de factores han erosionado esta diversidad, llegando al extremo de que en la actualidad, según suele afirmarse, sólo 30 cultivos proporcionan el $95 \%$ de la energía total que se obtiene de los alimentos, y cuatro de ellos (arroz, maíz, trigo y patata) suministran más del $60 \%$ de las calorías.

Ningún país en el mundo es autosuficiente en cuanto a los RFGAA para la producción agraria porque durante la historia de la Humanidad las plantas cultivadas han acompañado a todos los movimientos migratorios humanos. Por lo tanto, el acervo genético de la mayoría de los cultivos tiene incorporados genes que se han desarrollado en muchos lugares diferentes en los que se cultiva o se ha cultivado la especie y/o en los que crecen o han crecido sus parientes silvestres (Flores-Palacios, 1997). En un estudio reciente, Khoury, Achicanoy, Bjorkman, Navarro-Racines, Guarino, Flores-Palacios y Struik (2015) estiman la interdependencia media de los países respecto a los RFGAA en un $69 \%$, con valores mayores cuanto más alejados están los países de las zonas de origen de las especies vegetales que forman parte de sus dietas.

La dependencia alimentaria de unos pocos cultivos y de unas pocas variedades de cada uno de ellos puede crear graves problemas alimentarios. Un ejemplo clásico es la gran hambruna irlandesa de la patata entre 1845 y 1849 (Figura 1). El hongo Phytopthora infestans (tizón tardío) causó grandes pérdidas en las cosechas porque las variedades que se utilizaban eran genéticamente poco diversas y muy sensibles a este hongo. Como consecuencia de esta plaga, entre los muertos y los desplazados en ese periodo, Irlanda perdió una cuarta parte de sus habitantes. Se estima que en el país no se ha recuperado aún el nivel de población de antes de la hambruna. Otros ejemplos clásicos de desastres agrícolas de gran repercusión mundial por las enormes pérdidas de cosecha producidas y ocasionados por la falta de diversidad genética de los cultivos son el ataque del hongo Helmintosporium maydis al cultivo de maíz en varios estados de EEUU en los años setenta del siglo $\mathrm{XX}$, o el de roya a las plantaciones de caña cubanas durante 1980 . Estos casos, y otros similares se han multiplicado en las últimas décadas, poniendo en peligro la estabilidad económica y social de muchos países. Pese al impacto de estos desastres, actualmente una sola variedad de banana es objeto del $95 \%$ del comercio mundial.

Figura 1. Memorial de la Gran Hambruna en Dublín

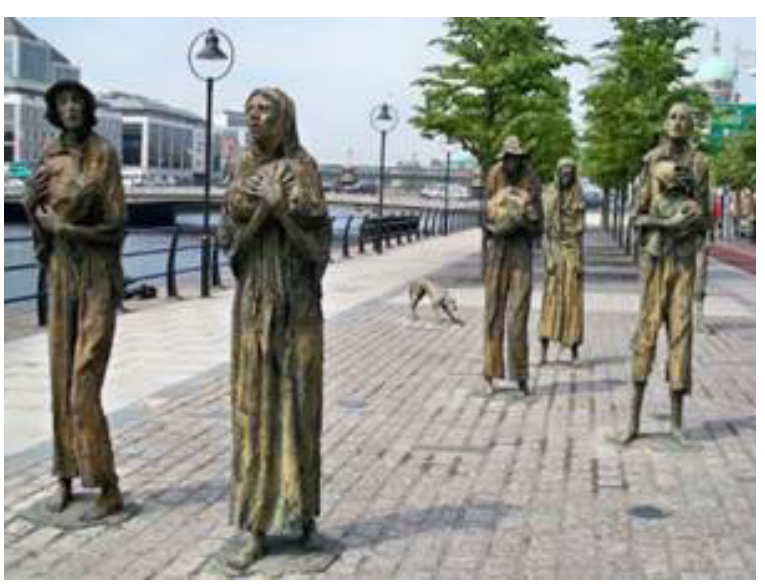

Fuente: http://innisfree1916.wordpress.com. 
A pesar de los incuestionables avances técnicos, sanitarios y sociales, el hambre sigue siendo uno de los problemas más acuciantes a nivel mundial. Según estimaciones de las Naciones Unidas, en el año 2050 la población humana pasará de los actuales 7.300 millones de habitantes actuales a casi los 9.300 millones, lo que implica que se tendrá que aumentar en un $70 \%$ la producción de alimentos, sin posibilidad de aumento de la superficie cultivable y de una forma respetuosa con el medio ambiente (FAO, Cómo alimentar al mundo en 2050).

La erradicación de la pobreza extrema y del hambre en el mundo fue uno de los Objetivos de Desarrollo del Milenio, que planteaba reducir a la mitad, entre 1990 y 2015 , el porcentaje de personas que padecen hambre. En 2015 este objetivo no se había cumplido por un escaso margen, ya que el porcentaje de malnutridos pasó del 23,3\% de la población mundial en el bienio 1990-92 al 12,9\% en el periodo 2014-2016 (Objetivos de Desarrollo del Milenio). Para avanzar en la lucha contra la pobreza y la desigualdad, en 2015 se adoptaron los Objetivos de Desarrollo Sostenible (ODS). El segundo objetivo de esta nueva agenda propone "Poner fin al hambre, lograr la seguridad alimentaria y la mejora de la nutrición, y promover la agricultura sostenible". Como uno de los elementos para cumplir este objetivo se señala: "Mantener la diversidad genética de las semillas, las plantas cultivadas y los animales de granja y domesticados y sus especies silvestres conexas, entre otras cosas mediante una buena gestión y diversificación de los bancos de semillas y plantas a nivel nacional, regional e internacional (...)".

La importancia que se atribuye en los ODS a la agrobiodiversidad y las colecciones de semillas para la seguridad alimentaria mundial supone el reconocimiento de una actividad conservacionista que se está desarrollando desde hace décadas. Ya en los años 30 del siglo XX, Harlan y Martini (1936) detectaron en las zonas de origen de la cebada cultivada y de sus parientes silvestres una apreciable pérdida de variabilidad. En los años 50, esta pérdida se identifica como un problema grave en el ámbito internacional, poniéndose entonces en marcha medidas globales para preservar la agrobiodiversidad. La reunión técnica organizada por FAO en 1961 sobre los recursos fitogenéticos y su conservación puede considerarse el punto de partida en el desarrollo del proceso internacional coordinado. Sucesivas reuniones y actividades promovidas por este organismo establecieron las directrices para solucionar los problemas técnicos relacionados con la recolección, conservación, caracterización y evaluación de germoplasma vegetal. Durante los años 70 y 80 se realizaron numerosas expediciones para recolectar semillas y materiales de plantación y se crearon bancos de germoplasma para asegurar su conservación ex situ a largo plazo. Se estima que actualmente existen más de 1.300 bancos de germoplasma en el mundo, con más de 7,4 millones de entradas (FAO, El Segundo Informe sobre el estado de los recursos fitogenéticos).

En los informes sobre el estado de los RFGAA en el mundo uno de los grupos más destacados es el de las leguminosas grano, que han sido y siguen siendo elementos clave de la seguridad alimentaria mundial. Según datos de la FAO el $15 \%$ de las muestras conservadas ex situ en todos los bancos de germoplasma del mundo son de leguminosas grano, lo que demuestra el interés que existe en la conservación de la diversidad de estas especies. Otro hecho que supone el reconocimiento de las leguminosas como elemento de la seguridad alimentaria es la incorporación de los recursos genéticos de garbanzos, almortas, lentejas, judías, guisantes, habas/vezas, altramuces, almortas y titarros en la lista del Anexo 1 del Tratado Internacional de Recursos Fitogenéticos Para la Agricultura y la Alimentación.

\section{LEGUMINOSAS GRANO. CARACTERÍSTICAS GENERALES}

La posición taxonómica de las leguminosas es la siguiente: Reino: Plantae; División: Magnoliophyta; Clase: Magnoliopsida; Subclase: Rosidae; Orden: Fabales. La familia Leguminosae (leguminosas) o Fabaceae (fabáceas), la más importante en el Orden Fabales, tiene aproximadamente 730 géneros y 19.300 especies, situándose como tercera familia de las Angiospermas en cuanto a número de taxones, después de las Orquidacea y Asteraceae y en el segundo lugar en importancia económica, después de las Poaceae. Siguiendo la clasificación de Flora Ibérica (Talavera et al., 1999) la familia se divide en tres subfamilias: Caesalpinioideae (cesalpinoideas), Mimosoideae (mimosoideas) y Papilionoideae o Faboideae (papilionáceas o fabáceas). Para algunos autores las dos últimas subfamilias serían también familias del Orden Fabales. En cualquier caso, la filogenia de este grupo sigue siendo tema de debate (Cardoso et al., 2012).

Al margen de estas divergencias, no cabe ninguna duda de que la familia o subfamilia de las Papilionoideae, con 478 géneros, 28 tribus y 13.800 especies es la más rica y extendida (Lewis, Schrire, Mackinder y Lock, 2005). Las tribus más importantes son: la tribu Fabeae, que incluye los géneros Lathyrus, Lens, Pisum, Vavilovia y Vicia; la tribu Ciciereae, con Cicer 
como único género; la tribu Phaseoleae, con los géneros: Dolichos, Glycine, Phaseolus y Vigna, entre otros; la tribu Genisteae cuyo representante más importante es el Lupinus y finalmente la tribu Aeschynomenae con el Arachis como representante más importante. Estas tribus incluyen las especies conocidas como legumbres o leguminosas grano, a las que las Naciones Unidas dedican el año 2016 (http://www.fao.org/pulses-2016). En la Tabla 1 se indican el centro de origen, tribu, nombre científico y nombre común de las leguminosas grano más importantes en el mundo.

Las características distintivas de este grupo de especies son:

- Un fruto en forma de vaina.

- Semillas con un elevado porcentaje de proteína, que se sitúa de media entre $20-25 \%$ (aunque hay excepciones como el altramuz amariIlo, con más del $40 \%$ y los yeros, con menos del $20 \%)$; bajo contenido en grasa, en torno al $1 \%$, salvo soja y cacahuete; y presencia de factores tradicionalmente considerados antinutricionales como antitrípsicos, hematoaglutininas, factores latíricos, glucósidos cianogénicos, sa- poninas, alcaloides, aminoácidos no proteicos, etc. En los últimos años está aumentando la consideración de estos factores como elementos nutraceúticos.

- Capacidad de fijación de nitrógeno atmosférico mediante la acción de bacterias del suelo de los géneros Rhizobium, Bradyrizobium y Sinorhizobium establecidas de forma simbiótica en las raíces de estas plantas.

Las leguminosas presentan una enorme diversidad de formas y estrategias de adaptación a diferentes entornos ecológicos, lo que en el caso de las formas cultivadas supone un elemento fundamental para la diversificación de los sistemas agrarios. De ellas se obtiene, además de alimento, aceite, combustible, tinta, maderas duras, medicamentos y productos químicos.

Sin ninguna duda las legumbres han sido, junto con los cereales, el sustento de la humanidad durante milenios. Los descubrimientos arqueológicos indican que probablemente fue una leguminosa, la almorta (Lathyrus sativus), el primer cultivo domesticado en la Península Balcánica alrededor del 6.000 a.C. (Kislev, 1989). En el siglo I de nuestra era, el autor hispano-

Tabla 1. Centros de origen, nombre científico y nombre común de las leguminosas grano

\begin{tabular}{|c|c|c|c|}
\hline Centro de Origen & Tribu & Especie & Nombre común \\
\hline \multirow{8}{*}{$\begin{array}{l}\text { Próximo Oriente y } \\
\text { Mediterráneo }\end{array}$} & Cicereae & Cicer arietinum $\mathrm{L}$. & Garbanzo \\
\hline & Fabeae & Lathyrus sativus L. y otros latiros & Almorta \\
\hline & Fabeae & Lens culinaris Medik. & Lenteja \\
\hline & Genisteae & Lupinus albus L. y otros lupinos & Altramuz \\
\hline & Fabeae & Pisum sativum L. & Guisante \\
\hline & Fabeae & Vicia ervilia Willd. & Yero \\
\hline & Fabeae & Vicia faba L. & Haba \\
\hline & Fabeae & Vicia sativa L. y otras vicias menores & Veza \\
\hline \multirow{4}{*}{ África Subsahariana } & Phaseoleae & Dolichos purpureusL. y otros dolicos & Dolico \\
\hline & Phaseoleae & Macrotyloma geocarpum (Harms) Merechal \&Baudet & Kestingiela \\
\hline & Phaseoleae & Vigna unguiculata(L.) Walp. y otras vignas & Caupí \\
\hline & Phaseoleae & Vigna subterranea (L.) Thouars ex DC. & Guanzú \\
\hline \multirow{3}{*}{ Norte de China } & Phaseoleae & Glycine max (L.) Merill. & Soja \\
\hline & Phaseoleae & Mucuna pruriens (L.) DC. y otras mucunas & Judía aterciopelada \\
\hline & Phaseoleae & Vigna angularis (Willd.) Ohwi \& H.Ohashi y otras vignas & Judia adzuki \\
\hline \multirow{5}{*}{ Sudeste Asiático } & Phaseoleae & Cajanus cajan (L.) Huth & Gandul \\
\hline & Phaseoleae & Canavalia gladiata (Jacq) DC. & Judía Jack \\
\hline & Phaseoleae & Phosphocarpus tetragonolobus (L.) DC & Judía alada \\
\hline & Phaseoleae & Vigna mungo (L.) Hepper & Judia mungo \\
\hline & Phaseoleae & Vigna radiata (L.) R. Wilczek & Judia mungo \\
\hline \multirow{6}{*}{ América } & Dalbergieae & Arachis hypogaea $\mathrm{L}$. & Cacahuete \\
\hline & Phaseoleae & Canavalia ensiformis (L.) DC. & Judía sable \\
\hline & Genisteae & Lupinus mutabilis Sweet & Altramuz \\
\hline & Phaseoleae & Phaseolus coccineus L. & Judía escarlata \\
\hline & Phaseoleae & Phaseolus lunatusL. & Judía de Lima \\
\hline & Phaseoleae & Phaseolus vulgaris L. & Judía común \\
\hline
\end{tabular}


rromano Columela en su obra De rei rusticae detalla las labores de cultivo y fechas de siembra de yeros, titarros y alholvas. En España, los agrónomos del siglo $X$ describieron la gran cantidad de legumbres que formaban parte de los sistemas agrarios, entre ellas habas y habichuelas, guisantes, garbanzos, lentejas, yeros, altramuces y alholvas.

En la actualidad, las leguminosas ocupan entre el $12-15 \%$ de la superficie mundial cultivable y suman el $27 \%$ de la producción mundial de alimentos. La producción de los cultivos más importantes, con la excepción del guisante, ha seguido durante los últimos 20 años una evolución creciente, tal como se muestra en la Figura 2. Gran parte de este incremento de la producción es atribuible a los países asiáticos y africanos.

El cultivo de leguminosas ofrece aspectos muy positivos desde el punto de vista de la protección del medio ambiente. Muchas de estas especies se cultivan en secano, con una necesidad mínima de inputs. Además, contribuyen a la mejora del suelo por su aporte de nitrógeno a través de las simbiosis bacterianas, protegiendo así tanto el suelo como el agua. Esta forma de aporte de nitrógeno ha sido muy importante hasta el desarrollo de procesos de síntesis de nitróge- no, y actualmente se reivindica en sistemas agrícolas de bajo impacto ambiental. Su inclusión en sistemas de rotación, especialmente de aquellas con sistemas radiculares profundos como la judía o el altramuz, reduce el consumo de energías fósiles y las emisiones de gases que provocan el efecto invernadero. Las características florales de las leguminosas las hacen especialmente atractivas para los insectos favoreciendo la biodiversidad en las zonas de implantación de estos cultivos. En otros artículos de este número de la revista Arbor se va a tratar en profundidad el beneficio sobre la salud del consumo de legumbres, que es sin duda otra bondad de estas especies.

\section{RECURSOS GENÉTICOS DE LAS PRINCIPALES LEGUMI- NOSAS GRANO}

A continuación se describen las leguminosas grano de importancia actual e histórica en España, atendiendo a su origen y evolución, taxonomía y situación de las colecciones de germoplasma en el ámbito mundial y europeo. Se incluye también información sobre las principales especies silvestres que forman parte del acervo genético de las leguminosas grano, ya que en muchas de ellas se han identificado genes de interés para la mayoría de los cultivos más importantes (Maxted y Kell, 2009).

Figura 2. Producción (izquierda) y superficie cultivada (derecha) de las especies más importantes de leguminosas grano en el mundo, 1993-2013
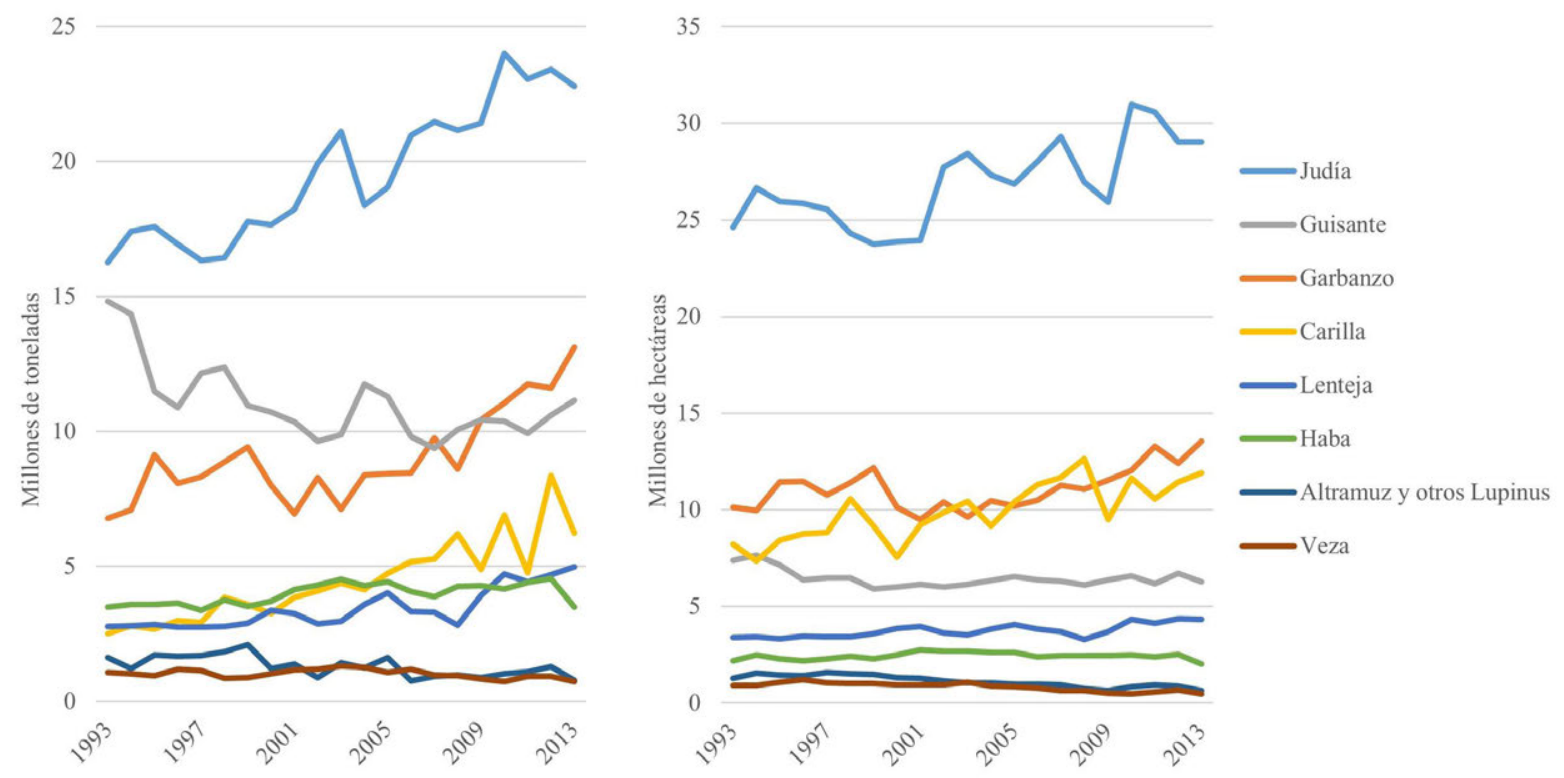

Fuente: FAOSTAT (2015). Nota: no se incluyen datos de producción y superficie cultivada de leguminosas cultivadas para consumo en verde (judías, guisantes) 
En todos los casos que ha sido posible se han consultado directamente las bases de datos de los bancos de germoplasma. La información sobre colecciones europeas se ha obtenido del catálogo EURISCO (http://eurisco.ipk-gatersleben.de). Este catálogo recopila la información de los inventarios nacionales de recursos fitogenéticos, que a su vez incluyen las accesiones conservadas en todos los bancos de cada país. También se ha consultado la información disponible en Genesys (www.genesis-pgr.org) y la publicada en el Segundo Informe Mundial sobre el estado de los RFGAA (FAO, El Segundo Informe sobre el estado de los recursos fitognéticos). En el caso de las colecciones españolas, la información más actualizada es la de las bases de datos del Centro Nacional de Recursos Fitogenéticos (CRF) del INIA. En todos los casos, cuando se describen las colecciones se indica entre paréntesis el número de entradas conservadas.

\section{Judía - Phaseolus vulgaris}

El género Phaseolus incluye aproximadamente 150 especies de las que tres, vulgaris, (judía común, alubia, poroto, frijol), coccineus (judía encarnada o ayocote) y lunatus (judía de luna o garrofón) se siembran de forma extensiva. Las evidencias arqueológicas indican que las judías ya se consumían 6.000 años a.C. La especie más extensamente cultivada es $P$. vulgaris, tanto para el consumo de la vaina en verde como de la semilla seca. Los datos morfológicos y de proteínas de reserva indican la existencia de dos centros de origen en los que la especie ha evolucionado de forma independiente, el Mesoamericano y el Andino (Gepts, Osborn, Rashka y Bliss, 1986). Tras su llegada a Europa, como consecuencia de la adaptación a los nuevos ambientes y por cruzamientos ocasionales entre formas de distintos orígenes, se ha originado una impor- tante diversidad morfológica y de uso. Este hecho ha llevado a proponer la Península Ibérica como un centro secundario de diversidad para la especie, al menos para las variedades de semilla blanca grande (SantaIla, Rodiño y De Ron, 2002). En España, el cultivo de judías sustituyó en parte al de las habas (Vicia faba) y las carillas (Vigna unguiculata).

La judía común es una especie anual, preferentemente autógama, diploide con $2 n=2 x=22$ cromosomas y un tamaño de genoma de aproximadamente $600 \mathrm{Mb}$. Se desarrolla en un amplio rango de ambientes desde el nivel del mar hasta los 3.000 msnm.

El principal interés en la conservación de germoplasma se centra por un lado en las variedades locales de la judía, y por otro en las especies silvestres emparentadas con $P$. vulgaris que se indican en la Tabla 2 junto con los caracteres de interés identificados.

En el ámbito internacional, el Centro Internacional de Agricultura Tropical (CIAT) desarrolla programas de mejora de judía y mantiene la colección más importante del mundo, con más de 36.000 entradas de 44 taxones. La colección está formada mayoritariamente por variedades locales, aunque también se conservan unas 1.900 entradas de Phaseolus silvestre (http:// isa.ciat.cgiar.org/urg/beancollection.do). La segunda colección mundial por su importancia cuantitativa es la del banco de germoplasma del USDA, con unas 13.000 entradas de las que unas 11.700 corresponden a la especie vulgaris. En la Empresa Brasileira de Pesquisa Agropecuaria (EMBRAPA), se dispone de una colección de más de 24.000 entradas de las que aproximadamente el $40 \%$ se identifican como formas locales, y el Instituto Nacional de Investigaciones Forestales, Agrícolas y Pecuarias (INIFAP) de México conserva 3.475 entradas, y una amplia colección de

Tabla 2. Parientes silvestres de la judía común asignados a cada uno de los acervos genéticos, y caracteres de interés localizados en estas especies

\begin{tabular}{|lll|}
\hline Acervo & Especies & Caracteres de interés \\
\hline Primario & $\begin{array}{l}\text { Phaseolus vulgaris var. aborigineus (Burkart) } \\
\text { Baudet }\end{array}$ & Rendimiento y factores del rendimiento \\
& Phaseolus albescens, P. coccineus, P. costarricense,, & Resistencia a la mancha angular de la hoja, \\
Secundario & P. dumoschyta, virus del mosaico verde, virus del \\
& & mosaico amarillo, Phytophthora y Rhizoctonia \\
\hline Terciario & Phaseolus acutifolius, P. acutifolius variedades & Resistencia a temperaturas \\
& acutifolius y tenuifolius, P. angustissimus, P. & \\
& carteri, P. fififormis, P. maculatus, P. parviflorus & \\
\hline
\end{tabular}

Fuente: Vincent et al., 2013. 
especies silvestres. En Europa destacan por su tamaño las colecciones del Leibniz-Institut für Pflanzengenetik und Kulturpflanzenforschung (IPK) de Alemania (8.446), Rusia (6.393), España (4.389), Hungría (4.047) y Ucrania (3.553).

Aunque la situación en cuanto a la disponibilidad de datos de caracterización y evaluación dista de ser la ideal, en todas las grandes colecciones se han establecido colecciones nucleares y se han desarrollado numerosos trabajos de localización de genes de interés (De Ron et al., 2015. Un ejemplo relevante es la obtención en el CIAT de 30 variedades de judía resistente a altas temperaturas utilizando como genitor la especie silvestre $P$. acutifolius.

\section{Guisante - Pisum sativum}

El guisante fue probablemente una de las primeras especies domesticadas en el Oriente Medio. La diversidad intra-específica de la especie es alta, y su cultivo abarca las zonas templadas de Asia, Europa y América y las regiones tropicales elevadas de África. En la clasificación de Maxted y Ambrose (2001) se diferencian siete taxones pertenecientes a tres especies.

1. Pisum sativum, con las subespecies sativus y elatius (Bieb.) Aschers. y Graebn. En la primera subespecie se diferencian las variedades sativum y arvense (L.) Poiret; y la subespecie elatius incluye las variedades elatius, brevipedunculatum Davis y Meikle y pumilio Meikle.

2. P. abyssinicum A.Br.

3. P. fulvum Sibth. y Sm.

El guisante es una planta herbácea predominantemente autógama con $2 \mathrm{n}=2 \mathrm{x}=14$ cromosomas y tamaño aproximado del genoma de $488 \mathrm{Mb}$. Maxted y Kell (2009) diferenciaron las variedades de Pisum sativum subsp sativum por el uso. La var. sativum (garden pea) sería la forma producida principalmente para el consumo humano, al que se destinan las semillas inmaduras frescas, enlatadas o congeladas y en algunos casos la vaina fresca cuando las semillas están aún poco desarrolladas (formas denominadas tirabeque o mangetout). La variedad arvense (field pea) se utiliza principalmente como forraje para la alimentación animal o como abono en verde para enriquecer el suelo en nitrógeno.

La Tabla 3 muestra las especies que forman el acervo genético del guisante.

Según los datos de Genesys consultados en noviembre de 2015, entre las colecciones de germoplasma de guisante destacan la del Servicio de Investigación Agrícola del Departamento de Agricultura de la Universidad del Estado de Washington (6.362 entradas), la del International Center for Agricultural research in the Dry Areas (ICARDA, 6.110), la del IPK de Alemania (5.789), y la del John Innes Center del Reino Unido (3.552). Sin embargo, otras fuentes consultadas como Smýkal, Kenicer, Flavell, Corander et al. (2013) citan como colecciones más importantes la del Institut National de la Recherche Agronomique (INRA) de Dijon (formada principalmente por materiales de mejora), la del Banco de Pullman en EEUU, la del Instituto Vavilov en Rusia, la Colección Australiana de Cultivos de Zonas Templadas, y la de ICARDA. En estas colecciones hay una cantidad muy importante de líneas mejoradas y stock genético. Si se considera la diversidad en cuanto a variedades locales, según estos autores, el banco de germoplasma más importante es el de Bari, en Italia, seguido del banco australiano, el de Pullman y el banco del Instituto Chino de Ciencias Agrarias (Warkentin et al., 2015). Según datos de Eurisco, en Europa las colecciones más relevantes en cuanto a su tamaño son la colección del John Innes Center en el

Tabla 3. Parientes silvestres de guisante asignados a cada uno de los acervos genéticos, y caracteres de interés localizados en estas especies

\begin{tabular}{lll}
\hline Acervo & Especies & Caracteres de interés \\
\hline Primario & Pisum sativum subsp. elatius & \\
\hline Secundario & P. abissinicum, P. fulvum & $\begin{array}{l}\text { Producción. Resistencia a frio, bruchidos y } \\
\text { Pseudomonas syringae pv pisi. }\end{array}$ \\
\hline Terciario & Vavilovia formosa & \\
\hline
\end{tabular}

Fuente: Vincent et al., 2013. 
Reino Unido (4.611 entradas), la del IPK de Alemania (3.471), la del Banco Nórdico (2.862), y los bancos de la República Checa (2.365) y Ucrania (2.362). Las colecciones de especies silvestres de este género son en general pequeñas y menos conocidas, destacando otra vez las del JIC (366) y la de Israel (333).

\section{Garbanzo - Cicer arietinum}

El garbanzo es originario del Creciente Fértil, donde también se ha observado la presencia de especies silvestres del mismo género, incluido el antecesor silvestre Cicer reticulatum Lad. (Ladizinsky, 1975). En la actualidad se cultiva en zonas cálidas tropicales y subtropicales. El género Cicer incluye 33 especies perennes, 8 anuales y una forma silvestre inespecífica, además de la única forma cultivada Cicer arietinum $\mathrm{L}$. El garbanzo es una especie herbácea, anual y autógama con un complemento cromosómico $2 n=2 x=16$. Las variedades de garbanzo se agrupan en dos tipos: desi, de semillas pequeñas, angulosas y pigmentadas, que se cultivan de forma preferente en el subcontinente indio, el este de África, y en Asia Central hasta el límite del mediterráneo, y kabuli, cuyas semillas son grandes y redondeadas y las flores de color blanco, que se cultiva ampliamente en la cuenca del Mediterráneo y Asia Central. Se ha secuenciado el genoma en una variedad de tipo kabuli (Varshney et al., 2013) y otra de tipo desi (Jain et al., 2013) y en ambos casos está su tamaño está en torno a las $740 \mathrm{Mb}$.

El garbanzo es la tercera legumbre a nivel mundial en cuanto a superficie de cultivo, después de las judías y los guisantes, y la más importante en los países en desarrollo.
Las especies silvestres del género que se han asociado al acervo genético de la especie, así como los caracteres de interés para la mejora que se han localizado en ellas se sintetizan en la Tabla 4.

En el ámbito internacional, los trabajos de mejora de garbanzo se ven limitados por la baja diversidad de las formas cultivadas, la poca disponibilidad de especies silvestres del género y la dificultad de mantener las especies perennes en campo (Ahmad, Gaur y Croser, 2005). Las colecciones de germoplasma de garbanzo más importantes del mundo son las que se conservan en el ICRISAT, que mantiene 20.600 entradas mayoritariamente de tipo desi, y el ICARDA, con aproximadamente 14.000 principalmente de tipo kabuli. Ambas mantienen también muestras de las especies silvestres del género Cicer. En cuanto a las colecciones europeas de garbanzo, las más importantes son las que se conservan en Rusia (2.764 entradas), Turquía (2.053), Ucrania (1.992), España (1.363) y Hungría (1.161).

\section{Lenteja - Lens culinaris}

La lenteja es una leguminosa del Viejo Mundo domesticada en el Oriente Próximo. En las últimas décadas la taxonomía del género Lens ha evolucionado como consecuencia del incremento de datos disponibles. Recientemente Cubero, Pérez de la Vega, Fratini, Erskine et al. (2009) han propuesto una reordenación del género en seis especies: Lens culinaris, L. ervoides, L. nigricans, L. lamottei, L. odemensis y L. tomentosus.

Lens culinaris subsp. culinaris es la forma más ampliamente cultivada del género. Es una especie autógama con un número cromosómico $2 n=2 x=14$ y un

Tabla 4. Parientes silvestres de garbanzo asignados a cada uno de los acervos genéticos, y caracteres de interés localizados en estas especies

\begin{tabular}{lll}
\hline Acervo & Especies & Caracteres de interés \\
\hline Primario & C. reticulatum & $\begin{array}{l}\text { Tolerancia a sequía y alta temperatura, Resistencia a Ascochyta, } \\
\text { Producción, Resistencia a nematodos }\end{array}$ \\
\hline Secundario & C. echinospermum & Producción, Resistencia a nematodos \\
\hline \multirow{2}{*}{ Terciario } & $\begin{array}{l}\text { C. atlanticum, C. bijugum, C. } \\
\text { chorassanicum, C.cuneatum, } \\
\text { C. incisum, C. judaicum, C. } \\
\text { pinnatifidum, C. yamashitae }\end{array}$ & Resistencia a Fusarium y Ascochyta \\
\hline
\end{tabular}

Fuente: Vincent et al., 2013. 
tamaño estimado del genoma de $4.063 \mathrm{Mb}$ (Arumuganathan y Earle, 1991). Botánicamente se diferencian los tipos macrosperma y microsperma en función del tamaño y la forma de la semilla (Barulina, 1930).

Las especies que conforman el acervo genético de la lenteja cultivada se muestran en la Tabla 5.

En el ámbito internacional, los trabajos más importantes de conservación y mejora en lenteja se han realizado en el ICARDA, que mantiene una colección de unas 12.000 entradas procedentes de 70 países. Son también importantes las colecciones de la Universidad de Washington (3.166), el Instituto Vavilov de Rusia (2.598), el Instituto de Agrobotánica de Hungría (1.069) y el Departamento de Recursos Genéticos de Turquía (1.068). Stefaniak y McPhee (2015) también incluyen entre las colecciones más importantes la Colección Australiana de Cultivos de Zonas Templadas con 5.250 entradas y la del centro de Recursos Genéticos de Plantas de Nueva Delhi (2.212). En Europa las colecciones que mantienen mayor número de entradas de esta especie son las de Rusia (2.598), Hungría (1.069), Turquía (1.068), Ucrania (958) y España (621).

\section{Haba, veza y otras vicias - Vicia spp}

El género Vicia incluye 216 especies, de las que aproximadamente 34 tienen usos conocidos. Se pueden encontrar en Europa, Asia, Norteamérica, en las zonas templadas de Sudamérica y en regiones tropicales del este de África. El centro de diversificación primaria se sitúa en el Próximo Oriente y en Oriente Medio. La taxonomía del género es compleja y ha sufrido más de 20 revisiones desde la clasificación original de Linneo del siglo XVIII. La organización taxonómica utilizada actualmente es la de Kupicha de 1976.

Las especies del género Vicia son mayoritariamente herbáceas y están ampliamente adaptadas a ambientes alterados. Respecto a su uso, el haba ( $V$. faba) se emplea en fresco en alimentación humana y como componente del pienso en alimentación animal. Entre las principales especies exclusivamente para alimenta- ción animal, en algunos casos con doble aptitud pienso - forraje, se pueden citar Vicia sativa (veza común), V. ervilia (yero), V. articulata (algarroba), V. narbonensis (alverjón o haba loca), $V$. villosa (veza vellosa), $V$. benghalensis (veza purpúrea) y $V$. pannonica (veza húngara). Entre las especies promisorias para este uso estarían V. hyaeniscyamus, V. noeana, y V. sativa subsp. amphicarpa que produce frutos aéreos y subterráneos.

El haba (Vicia faba) se cultiva desde el Neolítico y probablemente se domesticó en el oeste de Asia. El haba es una especie anual diploide, con $2 n=2 x=12$ cromosomas. Su genoma, con aproximadamente 13.000 Mb es, según los datos disponibles actualmente, el mayor entre las leguminosas grano (Ellwood et al., 2008). Muratova (1931) diferenció en las habas cultivadas las subespecies paucijuga y faba, esta última con tres tipos varietales en función del tamaño de la semilla: major, equina y minor. Otros autores (Harlan y de Wet, 1971) sólo reconocen la subespecie faba. Uno de los caracteres distintivos de esta especie es la alogamia entomófila parcial que puede variar ampliamente según las condiciones climáticas entre el $4 \%$ y el $84 \%$ (en torno al 50\% para el sur de España). También son variables los polinizadores, mayoritariamente himenópteros: en el sur de España es frecuente Eucera numida, mientras que en el noroeste de Francia se pueden encontrar abejorros, abejas y avispas (Cartujo, Suso, Pierre, Moreno y Le Guen, 1998; Suso, Moreno y Cubero, 1998).

El uso mayoritario de este cultivo es por sus semiIlas de gran valor para alimentación animal, principalmente de caballos y cerdos, aunque también hay formas mejoradas de la variedad major que se cultivan como especie de huerto y se emplean para consumo humano en fresco.

A pesar de los esfuerzos realizados, no se ha determinado ningún pariente silvestre de este cultivo, si bien algunos autores lo han asociado a $V$. narbonensis. Por lo tanto se considera que su acervo genético lo constituyen exclusivamente formas cultivadas primitivas, quedando la especie como taxón monoespecífico de la sección Faba dentro del género Vicia.

Tabla 5. Parientes silvestres de la lenteja asignados a cada uno de los acervos genéticos, y caracteres de interés localizados en estas especies

\begin{tabular}{lll}
\hline Acervo & Especies & Caracteres de interés \\
\hline Primario & L. culinaris subsp orientalis y L. odemensis & Resistencia a Ascochyta lentis \\
\hline Secundario & L. ervoides y L. nigricans & \\
\hline Terciario & L. culinaris subsp tomentosus y L. lamottei & Contenido en hierro alto \\
\hline
\end{tabular}

Fuente: Vincent et al., 2013. 
En cuanto a las colecciones de germoplasma de haba, todas incluyen principalmente variedades locales. Las más importantes son las de ICARDA (10.000), IPK de Alemania (2.018), INIA de España (1.310), Instituto Vavilov (1.000) e Instituto de Mejora Genética y Aclimatación de Polonia (960). A nivel europeo, según datos de EURISCO, destacan las colecciones de Alemania (2.395), España (1.673) Rusia (1.030), Reino Unido (753) y Bulgaria (732).

La veza (Vicia sativa L.) es una especie originaria del centro y sur de Europa y del área mediterránea, donde se pueden encontrar formas silvestres. Se han datado semillas en el Neolítico temprano que podrían corresponder a esta especie, aunque la evidencia definitiva de su cultivo se fecha en la época romana.

La veza común incluye formas con diversos números cromosómicos $(2 n=2 x=10,12,14)$. Para las condiciones ambientales de España se comporta en general como autógama, aunque se ha descrito un cierto grado de alogamia (Hanelt y Mettin, 1989). La clasificación de "Flora Ibérica" reconoce cuatro especies dentro del grupo $V$. sativa que son $V$. amphicarpa, $V$. angustifolia, $V$. cordata y $V$. sativa, diferenciándose dentro de esta última las subespecies sativa y macrocarpa. La veza común es una especie cultivada principalmente en secano por su grano, que se utiliza en la composición de un gran número de piensos, pero también por su forraje que, henificado en verde, alimenta al ganado vacuno, equino y ovino.

En la Tabla 6 se muestran las especies que conforman el acervo genético de la especie.

En el mundo hay 45 instituciones que conservan esta especie, siendo las colecciones más importantes las de ICARDA (3.119 entradas), Instituto Vavilov (2.817), Colección Australiana de Cultivos de Zonas Templadas (2.749), INIA de España (973), IPK de Alemania (773) y Universidad de Washington (764). En Europa se conservan entradas de esta especie en
26 países, destacando las de Rusia (2.817), España (974), Bulgaria (755), Alemania (752) y Reino Unido (410). Una gran parte de estas colecciones mantienen, además de la forma cultivada, especies silvestres emparentadas.

Los yeros (Vicia ervilia), las algarrobas (V. articula$t a)$ y los alverjones ( $V$. narbonensis) son otras especies del género Vicia que tuvieron gran importancia en la agricultura mediterránea tradicional. Actualmente están prácticamente desaparecidos de los sistemas productivos, a pesar de su gran potencial como fuente de proteína vegetal para la alimentación animal en sistemas agrarios de bajos insumos.

\section{Altramuz - Lupinus spp}

Del género Lupinus se han descrito hasta 275 especies, incluyendo formas herbáceas pero también algunos árboles, adaptadas a un rango muy amplio de condiciones ecológicas, desde los trópicos a Alaska. Las formas cultivadas se utilizan en alimentación humana y animal, en grano o como forraje, y a ciertas formas se les da un uso ornamental. Se puede desarrollar en suelos pobres y silíceos. Las semillas tienen un alto contenido en proteínas (33-45\%), aunque el contenido elevado de alcaloides hace necesarios procesos para su eliminación.

La sistemática de los altramuces es realmente compleja y está en constante revisión y, de hecho, en tiempos recientes se ha constatado tanto la extinción de alguna especie ( $L$. somalienesis) como la descripción de alguna nueva (L. anatolitus y L. mariae-josephi). Se diferencian dos acervos dentro del género, los altramuces o lupinos del Viejo Mundo, nativos de la cuenca mediterránea y del norte de África, y los del Nuevo Mundo (Aïnouche, Bayer y Misset, 2004; Drummond, 2008). Las formas del primer grupo son todas herbáceas, predominantemente autógamas, con hojas compuestas digitadas. Se diferencian dos grupos en función de la morfología de las semillas: las formas

Tabla 6. Acervo genético primario y secundario de la veza común

\begin{tabular}{ll}
\hline Acervo & Especies \\
\hline Primario & V. sativa subsps amphicarpa, devia, incisa, macrocarpa y nigra \\
\hline Secundario & V. barabacitae, V. grandiflora, V. pyrenaica y V. qatmensis. \\
\hline
\end{tabular}

Fuente: Maxted, 1995. 
de semilla lisa en la zona circunmediterránea y los de semilla rugosa que se distribuyen en el norte de África. En el Nuevo Mundo hay cientos de formas, muy variables en todas sus características, formas de reproducción y características citológicas (el número cromosómico $2 n$ varía entre 36 y 96). Los altramuces cultivados pertenecen principalmente a cuatro especies: $L$. albus (altramuz dulce), L. luteus (altramuz amarillo), L. angustifolius (altramuz azul) y L. mutabilis (tarwi).

Swiecicki, Kroc y Kamel (2015) han revisado recientemente las colecciones de 79 especies del género conservadas en 13 bancos de germoplasma. Según estos autores, la colección más importante es la de Center for Legumes in Mediterranean Agriculture (CLIMA) en la Universidad de Australia Occidental con más de 4.500 entradas, la del IPK de Alemania (2.767), INIA de España (1.843), el Centro de Germoplasma Vegetal del USDA en Pullman (1.293) y la empresa Poznan Plant Breeders de Polonia (1.169). Por especies, las colecciones más importantes son las de $L$. angustifolius (3.894) y L. albus (3.677), seguidas de las colecciones de L. luteus (1.799) y L. mutabilis (519).

En Europa hay información de 96 especies de Lupinus. Las colecciones más importantes de L. albus son las de Ucrania (750), España (742), Portugal (691), Rusia (495) y Alemania (240); de L. luteus Rusia (800), Ucrania (739), Portugal (361) y España (357); de L. angustifolius Rusia (840), España (680), Alemania (345) y Portugal (332) y de L. mutabilis Portugal (350) y Rusia (132). La mayoría de las entradas corresponden a las cuatro especies cultivadas por lo que resulta evidente la necesidad de recolectar material silvestre de algunas especies como L. diagitatus o L. princei.

\section{Almorta - Lathyrus sativus}

El género Lathyrus incluye aproximadamente 160 taxones que se distribuyen por las regiones templadas del Viejo y del Nuevo Mundo. Es difícil establecer una frontera entre las formas cultivadas y silvestres puesto que $L$. sativus y $L$. cicera, se pueden encontrar en ambos estados. La especie más cultivada del género ha sido la almorta (Lathyrus sativus), a pesar de la presencia en sus semillas de ácido beta-N-oxalil-L-alfa-betadiaminopropiónico (ODAP), sustancia causante de enfermedades neurodegenerativas como el latirismo cuando esta especie es un componente mayoritario de la dieta. Por esta razón, se recomienda que el consumo de almortas sea esporádico. En España también se han cultivado L. cicera (titarro), L. tingitanus (almorta tangerina), L. sylvestris, y L. aphaca con uso forrajero y L. odoratus y L. lathyfolius var albus como ornamentales (Mateo-Box, 1961). Entre otros usos minoritarios se puede citar el de $L$. ochrus como sustituto del café.

En el caso de la almorta, se han diferenciado dos grupos varietales según su origen: las almortas de origen mediterráneo, de semillas grandes y blancas aptas para consumo humano, y las formas de flores coloreadas y semillas más pequeñas y pigmentadas que se consideran formas más primitivas.

Tal como se indica en la Tabla 7, no se han identificado especies del acervo genético primario de la almorta. Sobre esta especie no se han desarrollado trabajos muy amplios de mejora, por lo que el uso de las especies indicadas en los acervos secundario y terciario es considerado como potencial.

\section{Carilla - Vigna unguiculata}

En España la Vigna unguiculata, conocida como judía, carilla, "judía de a metro" o caupí, se cultivaba antes del descubrimiento del Nuevo Mundo. En la actualidad el cultivo se extiende y consume de forma mayoritaria en el África subsahariana, en zonas con escasas precipitaciones y suelos pobres.

La colección más importante de Vigna unguiculata se conserva en el Instituto Internacional de Agricultura Tropical (IITA), localizado en Ibadan, Nigeria. Esta

Tabla 7. Especies de los acervos genéticos de la almorta

\begin{tabular}{ll}
\hline Acervo & Especies \\
\hline Primario & \\
\hline Secundario & Lathyrus chrysanthus, L. gorgoni, L. marmoratus, L. pseudocicera \\
\hline Terciario & Lathyrus amphicarpos, L. blepharicarpus, L. chloranthus, L. cicera, L. hierosolymitanus, \\
& L. hirsutus.
\end{tabular}

Fuente: Vincent et al., 2013. 
colección consta de 30.500 entradas, de las cuales la mitad proceden del oeste de África, zona considerada como el centro de diversificación de este cultivo. Las siguientes colecciones por su tamaño son la de la estación del USDA en Grifin (10.000 entradas) y la de la Universidad de California- Riverside (6.000 entradas).

\section{Otras leguminosas grano}

Otras especies de leguminosas grano tienen o han tenido un uso minoritario en Europa, y en algunos casos este uso ha sido notable. Por ejemplo, las alholvas (Trigonella foenum-graecum) han formado parte de los sistemas agrarios durante siglos. También son leguminosas desde el punto de vista botánico la soja, el cacahuete y diversas especies de la tribu Phaseolea que no se tratan en este capítulo dedicado a los recursos genéticos de especies de relevancia en España.

\section{COLECCIONES ESPAÑOLAS DE GERMOPLASMA DE LE- GUMINOSAS GRANO}

En España las leguminosas han sido un elemento clave en la agricultura y en la alimentación humana y animal hasta la segunda mitad del siglo XX. A partir de entonces entraron claramente en declive entre otras causas por el abandono del medio rural y por la sustitución de su uso en la composición de los piensos por proteína procedente de otros países, principalmente en forma de torta de soja. Las primeras actividades sistemáticas de recolección en el oeste peninsular, fi- nanciadas por el Banco Mundial y la FAO, comenzaron a finales de los años 70 (Alamán, Casanova y Bueno, 1983). Desde ese momento, las variedades locales de leguminosas han ocupado un lugar cuantitativamente muy importante en las actividades de recolección de germoplasma (Sánchez de Ron, de la Rosa Fernández, Varela y Peluzzo, 2006). Como dato representativo, en el periodo comprendido entre 1978 y 2014 el CRF ha organizado expediciones de recolección en 42 provincias españolas en las que se han recolectado un total de 4.599 entradas de leguminosas. Su distribución por géneros se indica en la Figura 3.

Los lugares donde es posible encontrar los recursos genéticos más valiosos y amenazados, es decir, las variedades locales, son generalmente las zonas de agricultura marginal, fuera de las grandes explotaciones comerciales. Normalmente se trata de huertos familiares en los que los agricultores mantienen variedades heredadas de sus antepasados, conscientes de la importancia de mantener ese patrimonio, y/o porque aprecian las características organolépticas de esas variedades por encima de otras variedades comerciales (Figura 4).

Además de la recolección directa, las colecciones españolas de recursos genéticos de leguminosas se han abastecido de donaciones por parte de otras instituciones españolas y de la incorporación de materiales de bancos internacionales de germoplasma como el del Centro Internacional de Investigaciones Agrícolas en Zonas Áridas (ICARDA).

Figura 3. Leguminosas recolectadas por el CRF en el periodo 1978-2014

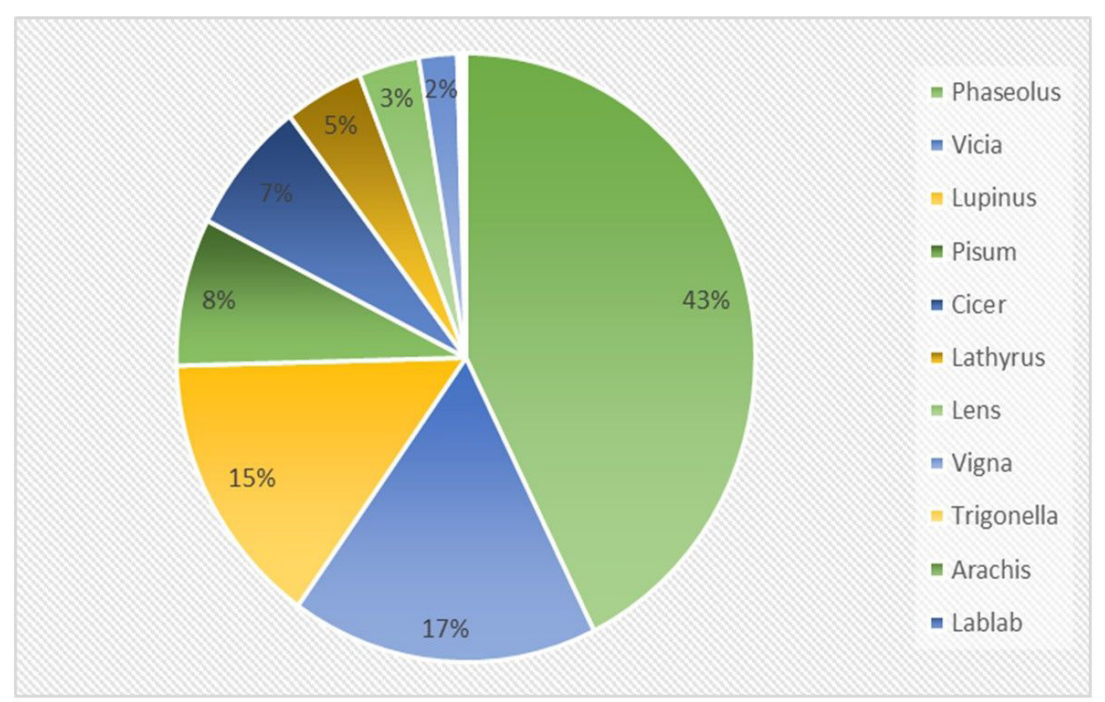

Fuente: elaboración propia a partir de las bases de datos del CRF.

\begin{tabular}{|l|c|}
\hline \multicolumn{1}{|c|}{ Género } & № de entradas \\
\hline Phaseolus & 1.964 \\
\hline Vicia & 789 \\
\hline Lupinus & 677 \\
\hline Pisum & 361 \\
\hline Cicer & 329 \\
\hline Lathyrus & 203 \\
\hline Lens & 156 \\
\hline Vigna & 98 \\
\hline Trigonella & 9 \\
\hline Arachis & 9 \\
\hline Lablab & 4 \\
\hline
\end{tabular}


Figura 4. Huertos tradicionales donde aún se cultivan variedades locales de leguminosas
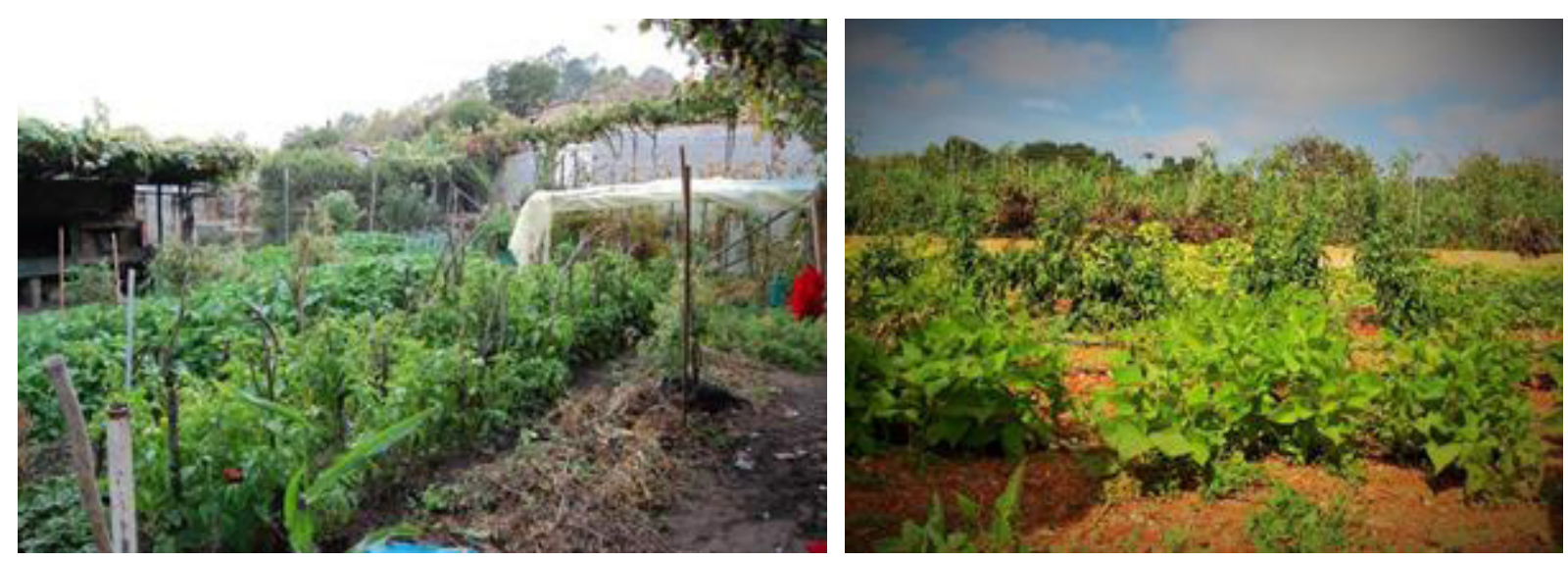

Fuente: CRF.

EI CRF es responsable de la conservación a largo plazo (colección base) y de la colección de trabajo e intercambio (colección activa) de las leguminosas grano conservadas en España, con la excepción de la colección nacional de altramuces, que se conserva en el Centro Centro Tecnológico Agroalimentario de Extremadura (CETAEX) de Badajoz y la de lentejas, que mantiene el Centro Agrario y Medioambiental de Albaladejito (CIAF, Cuenca). Otras colecciones españolas de germoplasma también incluyen leguminosas en sus colecciones de germoplasma (De la Rosa, Aguiriano y Fajardo, 2012). El tamaño de las colecciones activas, agrupando las entradas por género, se muestra en la Figura 5.
Por especies, las colecciones españolas de germoplasma más importantes son las siguientes:

Judía. Además de la colección del CRF hay que mencionar las de la Misión Biológica de Galicia del Consejo Superior de Investigaciones Agraria, el Servicio Regional de Investigación y Desarrollo Agroalimentario del Principado de Asturias, la Escuela Superior de Agricultura de la Universidad Politécnica de Cataluña, el Neiker y la Universidad de León. Estas colecciones incluyen materiales de trabajo procedentes de colecciones internacionales o se han establecido a través de recolecciones exhaustivas del germoplasma en la zona de influencia de cada centro de investigación (De Ron et al., 2015).

Figura 5. Distribución por géneros de las colecciones nacionales de leguminosas grano mantenidas en el CRF

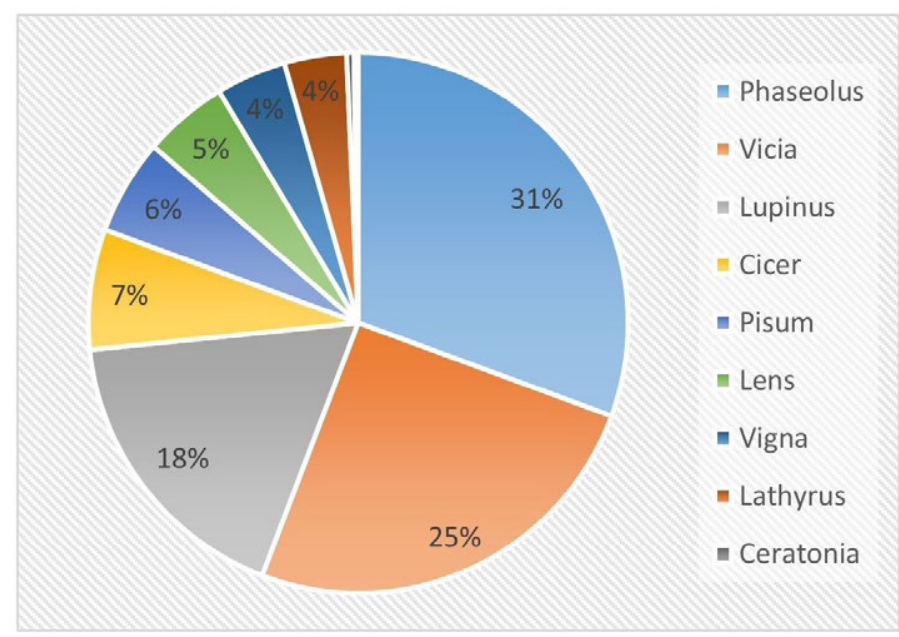

\begin{tabular}{|l|c|}
\hline \multicolumn{1}{|c|}{ Género } & N. entradas \\
\hline Phaseolus & 3.586 \\
\hline Vicia & 2.953 \\
\hline Lupinus & 2.064 \\
\hline Cicer & 842 \\
\hline Pisum & 669 \\
\hline Lens & 594 \\
\hline Vigna & 493 \\
\hline Lathyrus & 437 \\
\hline Ceratonia & 52 \\
\hline Lablab & 18 \\
\hline Trigonella & 11 \\
\hline
\end{tabular}


Guisante. En el CRF se dispone de 594 entradas de las 516 son variedades locales españolas. Además de esta colección, en el Instituto Tecnológico Agrario de Castilla y León se conserva una colección procedente de bancos internacionales que se ha utilizado en los programas de mejora de esta institución.

Garbanzo. La colección principal también se conserva en el CRF (842 entradas), y se complementa con una colección importante (452 entradas) en el Instituto de Formación Agraria y Pesquera de Córdoba, y otras menores en el ITACYL (44) y en el Centro de Conservación de la Biodiversidad de Tenerife Agraria (14). Estas colecciones son importantes por las peculiaridades que presentan los materiales procedentes de zonas ecogeográficas diferentes. Respecto al tipo de material, la mayoría (814 entradas) son variedades locales aunque también hay materiales procedentes de programas de mejora genética.

Lenteja. La colección base (594 entradas) se conserva en el CRF y la colección activa está en el CIAF de Cuenca. La mayoría de las entradas pertenecen a la especie cultivada, y además hay 43 muestras de $L$. nigricans y siete de L. lamottei.

Haba y veza. El género Vicia es el segundo en importancia cuantitativa entre los recursos genéticos de leguminosas. De un total de 2.954 entradas, 1.365 corresponden a la especie $V$. faba y 983 a $V$. sativa. La colección de haba se estableció en el IFAPA de Córdoba para satisfacer las necesidades de sus programas de mejora, a partir de materiales tanto de origen español como procedentes de bancos de germoplasma internacionales, principalmente del ICARDA. La colección de vezas incluye 984 entradas de las que 510 son de origen español y han sido el objeto de trabajos de caracterización morfológica, bioquímica y mediante marcadores moleculares ISSR. Otras especies del género Vicia con representación más reducida son yeros, algarrobas, veza villosa, veza húngara o alverjón. El interés de su conservación se debe a su valor en las rotaciones de cultivos dentro de las medidas agroambientales enfocadas a la agricultura verde, o como donantes de genes en los programas de mejora genética de otras plantas cultivadas con las que están emparentadas.

Altramuz. España es un centro importante de diversificación de altramuces. Las expediciones de recolección de las especies del género Lupinus que comenzaron en los años 70 y que se han mantenido a lo largo del tiempo han dado como resultado una importante colección de altramuces integrada por 2.157 entradas mayoritariamente de origen español y portugués. En total la colección incluye germoplasma de 12 espe- cies, entre las que destacan las especies cultivadas $L$. albus (756), L. angustifolius (703), L. luteus (366), L. gredensis (131) y L. hispanicus (94).

Almorta y titarro. La colección de Lathyrus incluye 438 entradas, principalmente de almortas (209) y de titarros (188), aunque también hay muestras de L. clymenum, L. tinguitanus, L. ochrus y L. hirsutus.

Carilla. En el CRF se conservan 488 entradas de Vigna unguiculata, de las cuales 124 son de origen español y el resto corresponden a donaciones de otros bancos.

En las páginas web del Inventario Nacional (http:// wwwx.inia.es/inventarionacional/) y del CRF (http:// wwwx.inia.es/coleccionescrf/) se pueden consultar los datos de pasaporte de todas las colecciones de leguminosas conservadas en España, así como información de caracterización morfológica.

En general, las colecciones se mantienen en un buen estado de conservación porque las semillas de las leguminosas son mayoritariamente ortodoxas, manteniendo niveles altos de viabilidad en condiciones de baja humedad y temperatura. Sin embargo, en algunos casos aún están pendientes trabajos de regeneración y multiplicación. Estas tareas se ven dificultadas porque la alogamia que presentan algunas especies de leguminosas hace necesario adoptar sistemas apropiados de control de la polinización.

La escasez de datos de caracterización y evaluación es uno de los motivos que se atribuyen a la falta de uso de las colecciones de germoplasma. Como respuesta a este problema se trabaja en el establecimiento de colecciones nucleares cuyo objetivo es representar la diversidad total de una colección en un tamaño significativamente menor de muestras, lo que permite concentrar los esfuerzos de caracterización y evaluación y facilitar el uso. En el caso de las colecciones españolas se pueden citar la colección nuclear de judía española (De la Rosa, Lázaro y Varela, 2000) o la de vezas (Marcos, García, De Andrés y De la Rosa, 2010) para cuyo establecimiento se han utilizado preferentemente variables morfo-agronómicas. En la actualidad se está poniendo a punto el potencial de uso de la información ecogeográfica de las zonas de distribución para la selección de elementos de las colecciones nucleares (Parra-Quijano, Iriondo, Torres y De la Rosa, 2011).

Es ampliamente reconocido el valor de las especies silvestres emparentadas con las cultivadas como donantes de genes de interés para la obtención de especies que contribuyan a una mayor sostenibilidad de los actuales sistemas agrarios. Estas especies están 
escasamente representadas en los bancos de germoplasma y sus hábitats son cada vez más frágiles, por lo que su recolección y conservación son urgentes.

El establecimiento y ampliación de colecciones de germoplasma para su estudio y utilización debe complementarse con medidas que permitan que las variedades locales de leguminosas sigan estando presentes en los sistemas agrarios. En general el rendimiento de estas variedades es menor que el de las variedades obtenidas en programas de mejora genética, por lo que para fomentar su cultivo es necesario diseñar y aplicar sistemas de compensación para los agricultores. Para favorecer la comercialización de semillas de estas variedades, en los últimos años la normativa europea y nacional ha incorporado al registro de variedades comerciales los conceptos de "variedad de conservación" y de "variedades de especies hortícolas desarrolladas para su cultivo en condiciones determinadas".

Finalmente, también queda pendiente cómo afrontar y resolver los retos jurídicos e institucionales a los que se enfrenta la conservación y utilización de la agrobiodiversidad, así como una apuesta clara de utilización de las leguminosas como elemento clave

\section{BIBLIOGRAFÍA}

Ahmad, F., Gaur, P. M. y Croser, J. (2005). Chickpea (Cicer arietinum L.). Genetic Resources, Chromosome Engineering and Crop Improvement-Grain Legumes, 1, pp. 185-214.

Aïnouche, A., Bayer, R. J. y Misset, M. T. (2004). Molecular phylogeny, diversification and character evolution in Lupinus (Fabaceae) with special attention to Mediterranean and African lupines. Plant Systematics and Evolution, 246, 3-4, pp. 211-222. DOI 10.1007/s00606-004-0149-8

Alamán, M. C., Casanova, C. y Bueno, M. A. (1983). Expedición de recogida de germoplasma vegetal en España (1981). Madrid: Instituto Nacional de Investigación y Tecnología Agraria y Alimentaria (INIA).

Arumuganathan, K. y Earle, E. D. (1991). Nuclear DNA content of some important plant species. Plant Molecular Biology Reporter, 9, 3, pp. 208-218.

Barulina, E. I. (1930). Lentils of the USSR and of other countries. Bulletin of Applied Botany, Genetics, and Plant Breeding. Supplement 40, pp. 1-319.

Cardoso, D., de Queiroz, L. P., Pennington, R. T., de Lima, H. C., Fonty, É., Wojciechowski, M. F. y Lavin, M. (2012). Revisiting the phylogeny of papilionoid legumes: New insights from comprehensively sampled early-branching lineages. American Journal of Botany, 99, 12, pp. 1991-2013. DOI 10.3732/ajb.1200380 en los sistemas agrarios que permitan que todos los recursos genéticos tengan, además de un valor de presente, un valor de futuro.

\section{CONCLUSIÓN}

En definitiva, las leguminosas, ricas en proteínas, mejoradoras de la calidad del suelo y favorecedoras de la diversidad pueden contribuir de forma decisiva al desarrollo sostenible de los agro-ecosistemas. En los sistemas agrarios tradicionales se ha generado, a lo largo de la historia, una abundante diversidad genética de leguminosas. La rápida transformación de los sistemas agrarios durante las últimas décadas, en España y en otros países, ha causado el abandono de especies y variedades. Afortunadamente los bancos de germoplasma conservan una representación de esta diversidad, evitando así su desaparición definitiva y facilitando su utilización en el presente y en el futuro. Este patrimonio genético tiene un enorme valor potencial para el desarrollo de una agricultura sostenible que responda a la creciente demanda de alimentos en el contexto de un mundo cambiante.

Cartujo, F., Suso, M. J., Pierre, J. Moreno, M. T. y Le Guen, J. (1998). Faba bean pollinating insects in south Spain: daily variation in abundance. En: EUCARPIA International Symposium on Breeding of Protein and Oil Crops, INRA, pp. 49-50.

Columella, L. J. M. (1996). Rei rusticae liber decimus: (carmen de cultu hortorum) (ed. de F. Boldrer). Pisa ETS.

Cubero, J. I., Pérez de la Vega, M., Fratini, R., Erskine, W., Muehlbauer, F. J., Sarker, A. y Sharma, B. (2009). Origin, phylogeny, domestication and spread. En: Erskine, W., Muehlbauer, F. J., Sarker, A. y Sharma, B. The lentil: botany, production and uses. CABI, pp. 13-33. DOI 10.1079/9781845934873.0013

De la Rosa, L., Lázaro, A. y Varela, F. (2000). Racionalización de la colección española de Phaseolus vulgaris L. Actas-Asociación Española de Leguminosas, 1, pp. 55-62.

De la Rosa, L., Aguiriano, E. y Fajardo, J. (2012). Colecciones de leguminosas grano conservadas ex situ, en la Red Española de Recursos Fitogenéticos. Actas de la Asociación Española de Leguminosas, 5, pp. 179-185.

De Ron, A. M., De la Rosa, L., Marcos, T., Lázaro, A., Casañas, F., Casquero, P. A., Ferreira, J. J. y Ruiz de Galarreta, J. I. (2016). Current bean germplasm collections and activities in Spain. Annual report of the Bean Improvement Cooperative. 59. (En prensa). 
De Ron, A. M., Papa, R., Bitocchi, E., González, A. M., Debouck, D. G., Brick, M. A., Fourie, D., Marsolais, F., Beaver, J., Geffroy, V., McClean, P., Santalla, M., Lozano, R., Yuste-Lisbona, F. J. y Casquero, P. A. (2015). Common Bean. En: de Ron, A. M. (ed.) Grain Legumes. New York: Springer, pp. 1-36. DOI 10.1007/987-14939-2797-5_1

Drummond, C. S. (2008). Diversification of Lupinus (Leguminosae) in the western New World: derived evolution of perennial life history and colonization of montane habitats. Molecular Phylogenetics and Evolution, 48, 2, pp. 408-421. http://dx.doi. org/10.1016/j.ympev.2008.03.009

Ellwood, S. R., Phan, H. T., Jordan, M., Hane, J., Torres, A. M., Avila, C. M., Cruz-Izquierdo, S. y Oliver, R. P. (2008). Construction of a comparative genetic map in faba bean (Vicia faba L.). Conservation of genome structure with Lens culinaris. BMC Genomics, 9, 1, 380. DOI 10.1186/1471-2164-9-380

Esquinas-Alcázar, J. T. (1993). La diversidad genética como material básico para el desarrollo agrícola. En: Cubero, J. I. y. Moreno, M. T (coords.). La Agricultura del Siglo XXI. Madrid: Mundi-Prensa, pp. 79-102.

Ferguson, M. E., Maxted, N., Slageren, M. V. y Robertson, L. D. (2000). A re-assessment of the taxonomy of Lens Mill. (Leguminosae, Papilionoideae, Vicieae). Botanical Journal of the Linnean Society, 133, 1, pp. 41-59. DOI 10.1111/j.1095-8339.2000.tb01536.x

Flores-Palacios, X. (1997). Contribution to the Estimation of Countries' Interdependence in the Area of Plant Genetic Resources. FAO Commission on Genetic Resources for Food and Agriculture. Background Study Paper, 7, Rev. 1. [En línea] Disponible en: ftp://ftp.fao.org/docrep/fao/meeting/015/j0747e.pdf

Gepts, P., Osborn, T. C., Rashka, K. y Bliss, F. A. (1986). Phaseolinprotein variability in wild forms and landraces of the common bean (Phaseolus vulgaris): evidence for multiple centers of domestication. Economic Botany, 40, 4, pp. 451-468.

Hanelt, P. y Mettin, D. (1989). Biosystematics of the genus Vicia L. (Leguminosae). Annual Review of Ecology and Systematics, 20, pp. 199-223.

Harlan, H. V. y Martini, M. L. (1936). Problems and results of barley breeding. En: United States Department of Agriculture Yearbook of Agriculture. Wahington, D.C.: United States Government Print Office, pp. 303-346.

Harlan, J. R. y de Wet, J. M. (1971). Towards a rational classification of cultivated plants. Taxonomy, 20, pp. 509-517.

Jain, M., Misra, G., Patel, R. K., Priya, P., Jhanwar, S., Khan, A. W., Sha, N., Singh, V. K., Garg, R., Jeena, G., Yadav, M., Kant, C., Sharma, P., Yadav, G., Bhatia, S., Tyagi, A. K. y Chattopadhyay, D. (2013). A draft genome sequence of the pulse crop chickpea (Cicer arietinum L.). The Plant Journal, 74, 5, pp. 715-729. DOI 10.1111/tpj.12173
Khoury, C. K., Achicanoy, H. A., Bjorkman, A. D., Navarro-Racines, C., Guarino, L., Flores-Palacios, X. y Struik, P. C. (2015). Where our food crops come from: A new estimation of countries' interdependence in plant genetic resources. Centro Internacional de Agricultura Tropical (CIAT). [En línea]. Disponible en: http://ciatlibrary.ciat.cgiar.org/Articulos_Ciat/biblioteca/CIAT_PB_25_ WHERE_OUR_FOOD_CROPS_COME_FROM.pdf

Kislev, M. E. (1989). Origin of cultivation of Lathyrus sativus and $L$. cicera (Fabaceae). Economic Botany 43, 2, pp. 262-270.

Kupicha, F. K. (1976). The infrageneric structure of Vicia. Notes from the Royal Botanic Garden Edinburgh, 34, pp. 287-326.

Ladizinsky, G. (1975). A new Cicer from Turkey. Notes from the Royal Botanic Garden Edinburgh, 34, 2, pp. 201-202.

Lewis, G., Schrire, B. Mackinder, B. y Lock, M. (eds.) 2005. Legumes of the world. Kew, UK: Royal Botanic Gardens.

Marcos, T., García, R. M., De Andrés, E. F., De la Rosa, L. (2010). Estudio de caracteres agro-morfológicos y fisiológicos, en una Colección Nuclear preliminar en Veza, conservada en el CRF-INIA. Actas de Horticultura, 55, pp. 153-154.

Mateo-Box, J. M. (1961). Leguminosas de grano. Barcelona: Salvat Editores.

Maxted, N. (1995). An ecogeographical study of Vicia subgenus Vicia. Systematic and Ecogeographic Studies on Crop Genepools. 8. Roma: International Plant Genetic Resources Institute.

Maxted, N. y Ambrose, M. (2001). Peas (Pisum L.) En: Maxted, N. y Bennett, S. J. (eds.). Plant Genetic Resources of Legumes in the Mediterranean. Dordrecht: Kluwer, pp. 181-190.

Maxted, N. y Kell, S. P. (2009). Establishment of a Global Network for the in situ Conservation of Crop Wild Relatives: Status and Needs. FAO Commission on Genetic Resources for Food and Agriculture, Background Study Paper 39. [En línea]. Disponible en: http://www.fao.org/docrep/013/i1500e/i1500e18a.pdf

Muratova, V. (1931). Common beans (Vicia faba L.). Bulletin of Applied Botany and Plant Breeding, suppl 50, pp. 285-298.

Parra-Quijano, M., Iriondo, J. M., Torres, E. y De la Rosa, L. (2011). Evaluation and validation of ecogeographical core collections using phenotypic data. Crop Science, 51, 2, pp. 694-703. DOI 10.2135/cropsci2010.05.0273

Romero Zarco, C. (1999). Vicia L. Flora iberica, 7, 1, pp. 360-416.

Sánchez de Ron, D., de la Rosa Fernández, L., Varela, F. y Peluzzo, A. (2006). Variedades tradicionales de leguminosas grano españolas recolectadas por el CRF-INIA (1977-2005). En: Rodríguez Conde, M. F., Sánchez Vioque, R. Giménez Alvear, M. J., de los Mozos Pascual, M. (coords.). Nuevos retos y oportunidades de las leguminosas en el sector agroalimentario español: 2as jornadas de la Asociación Española de Leguminosas, Cuenca, 25-27 de abril de 2006. Consejería de Agricultura. Junta de Comunidades de Castilla-La Mancha, pp. 207-214. 
Santalla, M., Rodiño, A. y De Ron, A. (2002). Allozyme evidence supporting southwestern Europe as a secondary center of genetic diversity for the common bean. Theoretical and applied genetics, 104, 6-7, pp. 934-944. DOI 10.1007./s00122-001-0844-6.

Smýkal, P., Kenicer, G., Flavell, A. J., Corander, J., Kosterin, O., Redden, R. J., Ford, R. Coyne, C. J., Mazted, N., Ambrose, M. y Ellis, N. T. (2011). Phylogeny, phylogeography and genetic diversity of the Pisum genus. Plant Genetic Resources, 9, 01, pp. 4-18. DOI 10.1017/S147926211000033X.

Stefaniak, T. R., y McPhee, K. E. (2015). Lentil. In: Grain Legumes. New York: Springer, pp. 111-140. DOI 10.1007/978-1-4939-2797-5_4.

Suso, M. J., Moreno, M. T, Cubero, J. I. (1998). Environmental and genotypic variation for outcrossing rate in faba beans (Vicia faba

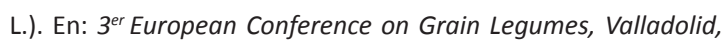
Spain, p. 446.

Suso M. J., Vishnyakova M., Ramos A., Duc G. y Ambrose M. (2011). An International Survey on State of the Art of Grain Legume Management in Gene Banks. Journal of Agricultural Science and Technology, 1, pp. 975-981.

Święcicki, W., Kroc, M., y Kamel, M. S. K. A. (2015). Lupins. In Grain Legumes. New York: Springer, pp. 179-218. DOI 10.1007/978-14939-2797-5_6.

Talavera, S., Aedo, C., Castroviejo, S., Romero Zarco, C., Sáez, L., Salgueiro, F. J. y Velayos, M. (1999). Flora Iberica: vascular plants of the Iberian Peninsula and Balearic Islands (Vol. 7 (I): Leguminosae (partim)). Madrid: Consejo Superior de Investigaciones Científicas.

Varshney, R. K., Song, C., Saxena, R. K., Azam, S., Yu, S., Sharpe, A. G., ... y Cook, D. R. (2013). Draft genome sequence of chickpea (Cicer arietinum) provides a resource for trait improvement. $\mathrm{Na}$ ture biotechnology, 31, 3, pp. 240-246. DOI 10.1038/nbt.2491
Vincent, H., Wiersema, J., Kell, S., Fielder, H., Dobbie, S., CastañedaÁlvarez, N. P., Guarino, L., Eastwood, R., León, B. y Maxted, N. (2013). A prioritized crop wild relative inventory to help underpin global food security. Biological conservation, 167, pp. 167, 265-275.

Warkentin, T. D., Smýkal, A. P. P., Coyne, C. J., Weeden, N., Domoney, C., Bing, D. J., Leonforte, A., Xuxiao, Z., Dixit, G. P., Boros, L., McPhee, K. E., McGee, R. J., Burstin, J. y Ellis, T. H. N. (2015). Pea. En: de Ron, A. M. (ed.) Grain Legumes. New York: Springer, pp. 37-83. DOI 10.1007/978-1-4939-2797-5_2.

\section{Recursos web}

FAO/Netherlands Conference on the Multifunctional Character of Agriculture and Land (1999). Agricultural Biodiversity. [En línea]. Disponible en: http://www.fao.org/mfcal/pdf/bp_1_agb.pdf

FAO. Tratado Internacional sobre los Recursos Fitogenéticos para la Alimentación y la Agricultura. [En línea]. Disponible en: http:// www.fao.org/pgrfa-gpa-archive/hnd/files/Tratado_internacional_sobre_los_recursos_fitogeneticos_para_la_alimentacion_y_ la_agricultura.pdf

FAO. Cómo alimentar al mundo en 2050. Foro de expertos de alto nivel. Roma 12-13 octubre 2009. [En línea]. Disponible en: http:// www.fao.org/wsfs/forum2050/wsfs-forum/es/

FAO. El Segundo Informe sobre el estado de los recursos fitogenéticos para la alimentación y la agricultura en el mundo. Roma, 2010. [En lína]. Disponible en: http://www.fao.org/docrep/014/ i1500s/i1500s.pdf

Objetivos de Desarrollo del Milenio. Informe de 2015. [En línea]. Disponible en: http://www.un.org/es/millenniumgoals/pdf/2015/ mdg-report-2015_spanish.pdf 